\title{
Os processos próprios de aprendizagem e a formação dos professores indígenas*
}

\section{Specific learning processes and indigenous teacher training}

\section{Adir Casaro Nascimento}

Resumo: O tema da formação de professores indígenas e a questão dos processos próprios de aprendizagem, colocados como um direito aos povos indígenas a partir da Constituição de 1988, tem como objetivo a ressignificação da prática pedagógica em contextos socioculturais particulares e dar visibilidade à educação indígena. Tendo como referência a criança indígena, sujeito que produz conhecimentos no contexto de suas particularidades e territorialidades, a reflexão aponta a necessidade de construção de novos aportes teóricos e de pedagogia(s) que dêem visibilidade a outras lógicas epistêmicas locais produzidas pela "colonialidade do poder", mas que se fazem diferentes da lógica dominante ocidental, no processo de formação de educadores indígenas.

Palavras-chave: Crianças indígenas. Processos próprios de aprendizagem. Formação de professores.

\begin{abstract}
Indigenous teacher formation and the issue of specific learning processes, as a right of the indigenous peoples derived from the 1988 Constitution, aim at the re-signification of pedagogical practices in specific socio-cultural contexts and at the visibility of indigenous education. Taking indigenous children as a reference, or rather, the agents that produce knowledge within the context of their particularities and territorialities, the essay points to the necessity of constructing new theoretical bases and a pedagogy that gives visibility to other local epistemic logics produced by "power coloniality". They are different from the dominant Western logic in the process of training indigenous educators.
\end{abstract}

Keywords: Indigenous children. Specific learning processes. Teacher formation.

\footnotetext{
* O texto faz parte das reflexões realizadas no contexto do Observatório de Educação Escolar Indígena - Núcleo Local/UCDB, financiado pela CAPES/DEB/SECAD/INEP - Projeto Formação de Professores Indígenas Guarani e Kaiowá em Mato Grosso do Sul: relações entre territorialidade, processos próprios de aprendizagem e educação escolar. Do Núcleo fazem parte: a Universidade Federal de Mato Grosso do Sul (UFMS); a Universidade Estadual de Mato Grosso do Sul (UEMS); a Universidade Federal da Grande Dourados (UFGD), além da Universidade Católica Dom Bosco (UCDB), como coordenadora. O mesmo projeto é financiado pela Fundação de Apoio ao Desenvolvimento de Ensino, Ciência e Tecnologia (FUNDECT) de Mato Grosso do Sul.

** Docente da Universidade Católica Dom Bosco. E-mail: <adir@ucdb.br>
} 


\section{Introdução}

Passados 500 anos de tentativas do Estado de homogeneizar culturalmente os povos indígenas através da educação escolar, constatamos nos últimos anos, com maior visibilidade, o papel desempenhado por estes povos no tocante a reações tanto nos níveis de resistência como nos de negociação, hibridação e tradução (BHABHA, 2003; CANCLINI, 1998). Dessa forma, a conquista dos movimentos indígenas nas últimas décadas rompe com o modelo curricular-metodológico de caráter homogeneizador e integracionista da escola colonialista que a eles era imposto e concentra-se em dois eixos epistemológicos garantidos pela Constituição Federal de 1988 e pela Lei de Diretrizes e Bases da Educação (Lei no 9394/96): permitir às escolas indígenas o uso da língua materna e respeitar seus próprios processos de aprendizagem.

Após séculos de um processo sistemático de subalternização, os movimentos indígenas na América Latina, em especial no Brasil, conquistam espaços para participar efetivamente das definições no sentido de protagonizarem a construção de outra escola indígena: uma escola que tem como eixo epistemológico os processos particulares, históricos, linguísticos e culturais produzidos em um contexto de encontros dinâmicos de muitas matrizes culturais - as eurocêntricas/ colonizadoras e as indígenas/locais - com outros sentidos de mundo. Pode-se dizer que esta outra escola politicamente definida pelos indígenas orienta-se pela decolonialidade (WALSH, 2009), que implica em reaprender a ver e em reavaliar a realidade das comunidades locais contemporâneas e criar "novos tipos de linguagens, compreensão e ação" (ESCOBAR, 2005, p. 147). Cada grupo social pode fazer a redescoberta, a releitura e a revalorização de suas histórias e das experiências específicas de suas culturas.

Concordamos com Maldonado-Torres (2007) quando referenda reflexões de Oliveira e Candau (2010) de que a escola ancorada na lógica do colonialismo exerceu mais do que o poder autoritário e político, de dominação e exploração de uma cultura sobre outras culturas, relações que parece poderem ser superadas com a chegada do fim jurídico-político do colonialismo. A lógica do colonialismo, para esses autores, constrói o que eles chamam de colonialidade: "a colonialidade do poder reprime os modos de produção de conhecimento, os saberes, o mundo simbólico, as imagens do colonizado e impõe novos [saberes]" (OLIVEIRA; CANDAU, 2010, p. 19). A colonialidade subalterniza, invade o imaginário do outro, ocidentaliza.

Autores como Mignolo (2003) e Walsh (2009) discutem a colonialidade do poder, como o fazem também os intelectuais indígenas (letrados ou não), e provocam a necessidade de problematizar a subalternização do conhecimento e a possibilidade de "recolocação de uma identidade". Para Mignolo (2003, p. 15), 
“as disciplinas das 'ciências humanas' já não podem permanecer como árbitro intelectual de projetos globais desvinculados das histórias locais". Com isso os referidos autores nos estimulam a investigar os saberes, conceitos e representações da cosmovisão ou das cosmovisões indígenas (aqui, particularmente os Kaiowá e Guarani) e o modo como esses conceitos, saberes e representações são inventados ou reinventados no contexto das experiências e histórias marcadas pela colonialidade. Instigam-nos, também, a outras perguntas na perspectiva de tornar visíveis outras lógicas, outras racionalidades e outras compreensões de mundo, para que se criem "novas comunidades interpretativas que ajudem a ver o mundo de uma perspectiva 'outra'. Esse enfoque quer se constituir como um projeto alternativo ao racismo epistêmico e à colonialidade do ser, do saber e do poder." (OLIVEIRA; CANDAU, 2010, p. 26).

Os povos indígenas, ao recontextualizarem a escola como espaço epistemológico e político norteado pelo uso da língua materna e pelo respeito aos processos próprios de aprendizagem, campos cognitivos e cosmológicos de construção de sentidos e significados, insurgem-se e apontam a necessidade de construir novos aportes teóricos e pedagogia(s) que deem visibilidade a outras lógicas epistêmicas locais produzidas pela "colonialidade do poder", as quais são diferentes da lógica dominante ocidental. Desconsiderar as crianças - principalmente as crianças indígenas - como produtoras de saberes faz parte do projeto de hierarquização das inteligências, da cognição e do conhecimento.

Quando o projeto de resistência dos indígenas do Brasil se consolida e produz um novo ordenamento jurídico que assegura aos índios o direito constitucional de permanecerem índios, as marcas que buscam garantir a afirmação étnica e cultural parecem estar diretamente orientadas para a necessidade da descolonização do pensamento. A Constituição de 1988, ao reconhecer o direito dos diversos povos indígenas de usar suas línguas maternas e seus processos próprios de aprendizagem, abre espaço para a legitimação de múltiplas espistemes. Como dirá Porto-Gonçalves (2005, p. 13, grifo do autor),

Em nuestra América mais que hibridismos há que se reconhecer que há pensamentos que aprenderam a viver entre lógicas distintas, a se mover entre diferentes códigos e, por isso, mais que multiculturalismo sinaliza para interculturalidade.

Contrariando a lógica estabelecida pelo eurocentrismo colonial de subalternização do conhecimento, as conquistas indígenas pautam-se pela legitimação de sistemas próprios (mesmo que ressignificados pelas trajetórias históricas de cada grupo) de produção de sentidos e significados que, em especial, para as escolas, caracterizam-se como um grande desafio. Escobar (2005, p. 159) questiona: "Como transformar o conhecimento local [indígena] em poder, e este conhecimento-poder em projetos e programas concretos?". 
Em nossas experiências de mais de duas décadas de formação de professores indígenas vimos percebendo que, apesar de termos a língua materna e os processos próprios de aprendizagem como eixos orientadores de nossas práticas, tínhamos (e temos) lacunas no sentido epistemológico que estes aportes conceituais deveriam produzir para a construção de uma escola indígena diferenciada. Têm sido escassos os estudos sobre os processos próprios de aprendizagem da população indígena brasileira no contexto de suas particularidades e territorialidades, principalmente se levarmos em consideração os aspectos específicos destes processos enquanto método/formas de ensinar e aprender transferidos para as obrigações e responsabilidades da escola indígena diferenciada e específica, numa perspectiva intercultural cuja dinâmica se dá a partir dos movimentos cognitivos e subjetivos de percepção e compreensão do mundo e de si mesma.

Acontece também que, nas relações que se estabelecem entre o dentro e o fora, surgem como que "espaços de fronteiras, entendidos como espaços de trânsito, articulação e troca de conhecimentos, assim como, espaços de incompreensões e de redefinições [...]", como teoriza Tassinari (2001, p. 49) ao identificar a escola indígena. Podemos dizer que também no caso das crianças Kaiowá e Guarani de Mato Grosso do Sul parecem se constituir os espaços de aprendizagens fora dos contornos da escola.

Dona Tereza, nãnderu/rezadora e considerada uma sábia anciã, a qual participa como mestre tradicional na formação dos professores indígenas, afirma que a educação guarani e kaiowá que orienta a formação de "um homem bom" está sustentada pelos princípios da comunicação espiritual (que está acima de qualquer religião ocidental que o Guarani professe), da ética do Guarani - que se orienta pela reciprocidade, da revelação (sonhos, inspiração feita pelos espíritos guarani) - por outra lógica de ver o mundo, pelo respeito para com o outro, pela alimentação tradicional e que as crianças aprendem com outras crianças. Nós, pesquisadores indígenas e não indígenas da educação escolar indígena guarani no Mato Grosso do Sul e outros estudiosos da pedagogia guarani temos observado que as práticas pedagógicas vividas entre professores e crianças/alunos indígenas são pautadas pela alegria, pelo respeito à vontade da criança, pela paciência (da espera, da contemplação) e pela reciprocidade (o não apego aos objetos). Também observamos que os processos de aprendizagem, ou seja, o ato de ensinar e aprender, se dão pela curiosidade (para aprender é preciso perguntar), pela observação da natureza e das outras pessoas, pela imitação (inspiração naquilo que a rodeia), pela autonomia, oralidade e escuta respeitosa da palavra, pelo diálogo e o silêncio e pela repetição (para aprender é preciso fazer muitas vezes).

Em vista desta percepção é que foi sendo construída, junto com os professores indígenas, a necessidade de realizar uma pesquisa que tivesse como transversalidade nos aproximar do que se coloca como "processos próprios de 
aprendizagem". Como definir o que significam processos próprios de ensino e de aprendizagem? Como cada grupo indígena, em suas particularidades, estabelece uma relação entre tradição e tradução ao experienciar modos próprios de conceber, construir e "educar", ou seja, de ser um Guarani, um Xavante, um Terena....hoje ? Como não caracterizar maneiras de aprender e maneiras de ensinar com ideias pré-fixadas de cultura como um artefato que ilustra coisas ou um conjunto de coisas do "mundo dos indígenas"? Como escapar do espectro da folclorização, ir além dos rituais, danças e apreender a lógica de leitura e compreensão do mundo, valores e saberes? Em uma primeira tentativa de minimizar esta lacuna nos propusemos realizar uma pesquisa com crianças Kaiowá e Guarani.

Quase sempre os estudos sobre a educação escolar indígena têm como ponto de partida a realidade dinâmica e ambivalente da escola entre os povos indígenas, porém, sempre vista sob a ótica do adulto. São raras as pesquisas realizadas com crianças indígenas que visam ouvir sua voz em primeiro plano; que procurem ouvir as suas vozes e as suas representações tendo como referência os seus contextos de aprendizagem, o lugar que ocupam na estrutura social de seu grupo, as suas atuações e suas produções (como são percebidas ou não), suas histórias recentes de reconfiguração territorial, das intervenções institucionais escolas, igrejas, órgãos de segurança, mídias, - de seus nexos sociais e identidade étnica. Neste sentido é preciso exercitar a vigilância espistemológica e metodológica para não reproduzir a superioridade ocidental no discurso de "dar voz aos sem voz". Sobre esta relação, Mato (2009, p. 86) afirma:

Cada uma dessas formas de saber tem suas próprias vozes, pelo menos em seus respectivos contextos, e todas elas são legítimas, pelo menos em seus respectivos contextos de produção e aplicação. Isso vale igualmente para todas as formas de saber, incluída a científica, nem mais nem menos.

Ouvir estas vozes contextualizadas tem sido um exercício de desconstrução de uma visão estereotipada sobre as crianças indígenas em geral e, em particular, sobre as crianças Kaiowá e Guarani do Mato Grosso do Sul. Pereira (2011, p. 76), ao caracterizar este conjunto de elementos que compõem a contextualização como "ambiente de vida", alerta que "talvez fosse mais apropriado colocar a palavra ambiente no plural, considerando a pluralidade de ambientes nos quais as populações Kaiowá e Guarani vivem atualmente em Mato Grosso do Sul.”

Dessa forma, por meio das representações de crianças Kaiowá e Guarani do Mato Grosso do Sul, o presente estudo, fruto da pesquisa em andamento, busca compreender a lógica de construção de conceitos, por um lado, no contexto da primeira socialização (família, comunidade e natureza) ou, como observam Gomes; Silva e Diniz (2011, p. 227), o reconhecimento de que "a forma de as crianças utilizarem seus espaços e tempos é determinante para que elas construam 
seus saberes e seu processo de apropriação da cultura, pertencimento comunitário". Isto impulsiona, segundo os mesmos autores, a "teorizar para além dos processos escolares, a partir de um amplo espectro de etnografias" (GOMES; SILVA; DINIZ, 2011, p. 262), deslocando o olhar do espaço escolar enquanto lugar fixo de aprendizagens, de produção de conhecimento. Por outro lado, não se podem considerar uma ruptura, mas um continuum, as mudanças que sofrem estes conceitos e estes saberes no contexto do que chamamos de socialização secundária (o espaço da educação escolar). Assim se poderá contribuir para a construção de projetos político-pedagógicos numa perspectiva intercultural e, por consequência, qualificar a formação de professores indígenas a partir de um novo contorno teórico - quer do ponto de vista epistemológico, quer do ponto de vista metodológico/pedagógico - que atenda às exigências de uma educação escolar indígena diferenciada e específica, bem como avaliar os projetos pedagógicos em andamento nas aldeias e os seus resultados práticos no que diz respeito ao aspecto epistemológico (NASCIMENTO, 2006).

Com base na Antropologia, na Pedagogia e nos estudos culturais, a produção de dados apoia-se em entrevistas, desenhos, fotografias e filmagens realizados pelas crianças que contemplem a interpretação dos sentidos e significados antes da frequência escolar e depois do ingresso na escola, nas reservas de Taquapery, Caarapó e Porto Lindo, situadas, respectivamente, nos municípios de Coronel Sapucaia, Caarapó e Japorã/MS. Temáticas iguais (conceitos de mata, animais, remédio, terra, espaço, jogos, família, festas, criação, mundo, escola, gênero, entre outros) permitem proceder à comparação das distintas representações construídas no contexto da formação primária da cultura local e às traduções, que são realizadas no contato com informações de outras culturas.

Ao orientar a nossa atenção para a cosmovisão da criança indígena contemporânea trazemos, ao mesmo tempo, uma noção de cultura que, "ao invés de ser vista apenas como um componente extraordinário da vida social, penetra na vida cotidiana, tendendo a ser considerada como uma das categorias centrais indispensáveis para dar inteligibilidade ao mundo" (GABRIEL, 2006, p. 32). Neste sentido, o "fora da escola" caracteriza-se também como um espaço de tradução, resistência e hibridação cultural que possibilita a formação de múltiplas identidades e cosmovisões, bem como de cosmovisões multirreferenciadas. Nesta direção a investigação tem se orientado também pela noção de aprendizagem constitutiva das práticas sociais/culturais vinculadas ou não à escola (GOMES; SILVA; DINIZ, 2011).

Apesar deste papel quase secundário das crianças indígenas nas atuais pesquisas sobre a educação escolar entre estes povos, constata-se, desde o iní- 
cio, o papel central e a preocupação da comunidade com o futuro e a educação de suas crianças. Professores Kaiowá e Guarani1 ${ }^{1}$ em um debate sobre as crianças de sua etnia, assim se manifestaram:

A criança é a esperança para o grupo, a educcção é feita pela oralidade, prática, exemplos, de conselhos [...] a educação não é limitada, é infinita. Cada fase a criança vai estar recebendo uma educação diferente[...] a educação da escola é diferente da educação da família. Idade para ir para a escola: $7 / 8$ anos - antes dessa idade a criança depende, precisa da educação da família para aprender a obedecer mitos, preparar a família oralmente e prática.... Crianca significa herdeiro: levando o conhecimento de geração para geração. Uma criança feliz é aquela que tem carinho, afeto, exemplos. A criança é muito observadora. (grifos nossos).

A criança começa a andar, a falar e é aconselhada sem violência. Ela aprende por imitação: a respeitar os mais velhos, o sagrado, relacionado muito com a natureza. A idade mínima para ingressar na escola seria oito anos. Separar muito cedo da família... Toda aprendizagem da família não vai preservar: danças, rezas... Para a criança ser feliz: ter liberdade e participar de todos os eventos indígenas porque em todos esses momentos estão sendo vistos pelo Pai Nhanderu.

Outra preocupação é manifestada por um rezador Kaiowá:

Hoje não se fazem como antigamente os rituais de cada fase da vida, por isso vemos as crianças sem rumo, tanta coisa acontecem no nosso dia, não se respeitam, vemos tantas coisas ruim acontecendo porque eles não tem desígnio dos espíritos bom para guiá-lo na sua caminhada, precisa voltar a fazer isso mais rápido possível. Ela é muito importante na vida dos Guarani/Kaiowá. (Depoimento de um Ñanderu- rezador Kaiowá).

É possível evidenciar nestas falas elementos que caracterizam o jeito de ensinar e aprender, ou seja, o desenho de uma pedagogia kaiowá e guarani. Assim, apesar do processo violento e autoritário da prática colonizadora ocidental de impor certa hegemonia do ensinar e aprender e de subaltenizar os saberes desses povos, estes encontraram estratégias de sobrevivência cultural para que seus saberes, mesmo que hibridizados e ressignificados, não desaparecessem. Neste caso estamos inferindo como elementos que constituem a cosmovisão de cada povo suas estruturas sociais, suas práticas socioculturais e religiosas, suas formas de produção de conhecimento, seus processos e métodos de ensino-aprendizagem.

\footnotetext{
${ }^{1}$ Durante etapa de formação de professores, no Projeto Ara Verá - Formação de Professores Kaiowá e Guarani - Novembro de 2005 - Dourados/MS.

${ }^{2}$ Depoimento ouvido por Elda Vasques Aquino (pesquisadora guarani) na Aldeia de Amambaí/MS.
} 
Podemos reafirmar esta compreensão no manifesto que faz Benites $(2012)^{3}$, ao descrever "o processo de educação básica das crianças guaranikaiowá", caracterizando a base da organização social e da família extensa, as relações estabelecidas tendo-se em vista gênero e ciclos de crescimento e, sobretudo, o que ainda considera como "o estado e a característica de cada alma gradativamente assentada no corpo da criança". Para Benites (2012),

A lógica educativa decorre de uma situação de aconselhamento individual, coletivo e diálogo diário com os seus membros sobre o modo de ser e viver adequado no contexto atual. No passado, os líderes femininos e masculinos das famílias extensas eram, em sua maioria, basicamente xamãs e os seus auxiliares. Por fim, hoje em dia, nem todos os líderes-suporte de cada família extensa são xamãs, mas eles agem fundamentalmente de modo muito similar aos anteriores, sendo caracterizados como pessoas religiosas, pacientes, acolhedoras, que de fato possuem também vasta experiência de ouvir, comunicar-se, educar e aconselhar as crianças, respeitando as distintas faixas etárias. Embora os espaços territoriais e contextos anteriores tenham mudado ao longo do tempo, em parte o modo de ensinar as crianças permanece como era no passado, isto é, o ensino doméstico é realizado através do método oral, repetitivo e contextualizado, baseado nos interesses reais de cada família extensa contemporânea.

\section{As crianças indígenas Kaiowá e Guarani e as representações acerca dos conceitos locais}

A criança indígena tem um papel muito importante dentro de sua sociedade particular. Reconhecer isto é assumir que ela é um ser completo em suas atribuições, um ser ativo na construção das relações em que se engaja e parte integrante da sociedade, participante e construtora de cultura. A partir de sua interação com outras crianças (brincadeiras, jogos, afazeres domésticos, caminhadas, cumprimento de rotinas) as crianças acabam por constituir seus próprios papéis e identidades. Estudos realizados por Brand (2003), Cohn (2005), Lopes da Silva e Ferreira (2001), Nunes (2002), Nascimento, Aguilera Urquiza e Vieira (2011), Pereira (2002) e Bergamaschi (2007), entre outros, ancorados em conhecimentos que têm como suportes a História, a Antropologia e a Pedagogia, reconhecem que:

- as crianças são agentes ativos, atores sociais; são capazes de criar, de reinventar, reelaborar sentidos e traduções sobre os fenômenos que as cercam e experienciam e transmitem culturas e saberes, inclusive para o mundo dos adultos;

\footnotetext{
${ }^{3}$ Tonico Benites-Guarani-Kaiowá, mestre e doutorando em antropologia do MN/UFRJ/RJ. Foi consultor do MEC, no ano de 2011, para a implantação do Território Etnoeducacional do Cone Sul/MS - Guarani e Kaiowá. Texto divulgado no dia 25 de abril de 2012 via e-mail: <tonicobenites2011@hotmail.com>.
} 
- as relações entre infância e lugar, infância e território, assim como as condições materiais e simbólicas de cada espaço, exigem reconhecer a existência de culturas plurais também para as crianças, que estabelecem relações sociais e cognitivas entre si e com os adultos dentro da lógica de organização social de cada grupo;

- as brincadeiras infantis têm-se mostrado de grande importância na transmissão cultural, pois por meio delas a criança está experimentando o mundo e as reações, tendo, assim, elementos para desenvolver atividades sem a intervenção de um adulto; e entre si estabelecem um lugar identitário, material e simbólico;

- no "mundo" da criança indígena se faz a presença da bricolage, pois, usando do material de que dispõe, ela constitui novos universos trazendo algo de si mesma para esse universo, que nunca se completa, ressignificando conceitos e construindo suas identidades (LÉVI-STRAUSS, 1976);

- e, ainda, que

[...] pensar a socialização das crianças exige matizar a heterogeneidade destas [das] figurações em seus módulos organizacionais com dimensões escalonadas em ordem de grandeza, buscando identificar, em cada caso particular, como práticas e valores instituem características próprias e exclusivas a socialização das crianças. (PEREIRA, 2011, p. 84).

As observações realizadas em contato com crianças indígenas em seus cotidianos têm evidenciado o modo próprio de ser das crianças indígenas Kaiowá e Guarani seguindo a perspectiva da pedagogia indígena,

[...] a criança aprende experimentando, vivendo o dia da aldeia e, acima de tudo acompanhando a vida dos mais velhos, imitando, criando, inventando, sendo que o ambiente familiar, composto pelo grupo de parentesco, oferece a liberdade e a autonomia necessárias para esse experimentar e criar infantil. (NASCIMENTO, 2006, p. 8).

Esta vivência pôde ser constatada em pesquisa realizada por Landa (2005, 2011) na reserva Porto Lindo/Japorã/MS, onde, em todas as atividades que foram acompanhadas, havia a presença de crianças de diferentes faixas etárias, desde crianças de meses, que permaneciam no colo das mães ou parentes até crianças maiores e adolescentes. Em reuniões com órgãos públicos, em cursos variados feitos pelas mães, em conversas informais, na realização de tarefas cotidianas como buscar água, coletar lenha ou visitar parentes, as crianças são parte integrante do universo adulto. 
Landa ${ }^{4}$ (2011, p. 64) registra, ainda, ser possível observar

[...] que existe, efetivamente, uma segurança social muito grande por parte das crianças [...]. Após o período de amamentação, que em geral se estende até dois anos de vida, quando passam a dominar completamente a marcha, as crianças ganham muita autonomia, pois é comum encontrá-las sozinhas pelas estradas brincando ou andando em grupos de variadas idades [...].

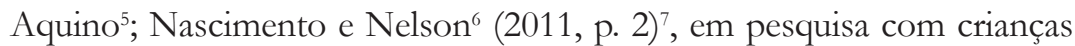
Kaiowá e Guarani, na Aldeia de Amambaí, afirmam que

[...] as crianças que ainda não foram para a escola, estão adquirindo conhecimentos proveitosos no seio familiar e como os processos próprios de aprendizagem kaiowá e guarani estão presente em cada momento, seja ela na ida para roça, no caminho percorrido entre as trilhas para o rio, indo para cidade, fazendo coletas de frutos fora e dentro da aldeia, acompanhando os pais na igreja, nas rezas e outros. Todos os lugares são espaços que se transformam em escola tradicional.

Para Aquino ${ }^{8}$, pesquisadora indígena que mora na aldeia e convive dia a dia com a dinâmica da comunidade, é preciso "entender como os processos de aprendizagem trazem à tona aquilo que há muito tempo se questiona: O que é ser criança? Como vivem? O que é infância?”. Afirma ela:

Se pararmos para pensar parece fácil de responder, mas quando surge a pesquisa, vê-se que nao é tão simples assim.O modo de aprender e com quem se aprende são das mais diversas. A família é a que tem mais responsabilidade para educá-las e a desenvolver técnicas de ser um bom kaiowá e guarani. As mães kaiowá e guarani são muito permissivas aos seus filhos, dando liberdade para que as crianças aprendam a ser um adulto atuante, para isso passa por rituais desde a gestação.

\section{Acrescenta a autora:}

Cada uma das diversas comunidades elabora suas próprias explicações a respeito do mundo, dos fenômenos da natureza, dos espíritos, dos seres sobre-

\footnotetext{
${ }^{4}$ Beatriz Landa faz parte da equipe de pesquisa com crianças indígenas Kaiowá e Guarani. Doutora em arqueologia realiza a investigação tendo como referencial a abordagem etnoarqueológica. Observatório em Educação Escolar Indígena/UCDB.

${ }^{5}$ Professora indígena Guarani, mestranda do Programa de Pós Graduação em Educação/UCDB - Mestrado e Doutorado - Bolsista do Observatório em Educação Escolar Indígena/UCDB.

${ }^{6}$ Professora indígena Guarani, acadêmica da Licenciatura Intercultural Teko Arandu/UFGD - Bolsista do Observatório em Educação Escolar Indígena/UCDB.

7 Texto apresentado no IV Seminário Povos Indígenas e Sustentabilidade: saberes tradicionais e formação acadêmica - 15, 16, 17 e 18 de agosto de 2011. Disponível em: <http://www.neppi.org/ eventos/4sustentabilidade>.

${ }^{8}$ Depoimento em 2010.
} 
naturais e, também, do momento em que surgiram os seus ancestrais. Portanto é necessário que se desenvolva pesquisas com urgência sobre a capacidade de relacionamento que as crianças têm com os mais velhos e a sua visão a respeito do mundo em que se encontra, os conhecimentos que vão adquirindo durante a infância é de suma importância para um bom desenvolvimento entre adultos e crianças, basta os adulto entendê-las.

Ao contrário do que costuma acontecer na chamada "sociedade ocidental", entre os Kaiowá e Guarani as crianças estão presentes em todas as atividades do cotidiano. Quando pequenas acompanham as mães a todos os lugares; quando mais crescidas, perambulam pelos espaços da aldeia, através das trilhas que levam às casas da parentela, até que chega a idade escolar, quando o tempo e o espaço começam a ser demarcados por outras lógicas.

No caso das crianças Kaiowá e Guarani a liberdade para viver o que Nunes (2002) chama de "as brincadeiras sazonais" decorre diretamente do confinamento e do contexto gerado pela perda da terra. A autonomia gerada por este tipo de educação é proveniente das condições precárias que os pais e, em especial, as mães vivenciam para manter seus filhos (dadas as condições de confinamento que desestruturam as suas formas de subsistência e de organização social). Nunes (2002) afirma que quando as crianças brincam, elas estão contextualizando e elaborando o contexto social em que vivem. Para ela, a atividade lúdica e a constatação de que a brincadeira faz parte do dia a dia servem para evidenciar as dimensões da cultura e da vida social, com tempo e espaço, presentes nas brincadeiras sazonais. No ensaio "No tempo e no espaço: brincadeiras das crianças A'uwê-Xavante", a autora observa:

[...] a fase que corresponde à infância é marcada pelo que consideramos ser uma enorme liberdade na vivência do tempo e do espaço, e das relações societárias que por meio destes se estabelecem, antecedendo ao período de transição para a fase adulta que, então, inaugura limites e constrangimentos muito precisos. (NUNES, 2002, p. 65).

Segundo Cohn (2005), para entender a criança indígena é preciso primeiro entender o mundo em que ela está inserida: suas condições de vida, seu ambiente, seu cotidiano, suas brincadeiras criatividades, explorando o modo como ela experimenta e se expressa na vida social. De acordo com a autora, a criança é um agente que constrói suas relações e lhes atribui sentidos, é um ator social ativo e produtor de cultura. Através da brincadeira a criança aprende por imitação, definida como "instinto social" que a faz tornar-se gradativamente um "ser social pleno".

A partir de estudos de Nascimento (2006) é possível descrever com mais detalhes os elementos culturais destes povos e o cotidiano das crianças indígenas: 
[...] as crianças aprendem olhando, observando toda a realidade, estão presentes em toda a parte na aldeia e nas áreas circundantes e quase não há punições. A criança tem liberdade, permissividade e autonomia, experimentando e participando da realidade concreta do dia a dia, seus conflitos e contradições, estão perfeitamente articuladas com aprendizagem e responsabilidades na vida, que nas comunidades indígenas iniciam muito cedo. (NASCIMENTO, 2006, p. 8).

Afirma Pereira, antropólogo que estuda o povo Kaiowá e Guarani do Mato Grosso do Sul:

A criança Kaiowá recebe uma educação que lhe permite grande liberdade para seguir as motivações de seu desejo de descobertas. Os Kaiowá acham natural que a criança seja curiosa, inquieta e interessada por tudo que representa novidade. Existe um provérbio que diz "ñande mitãramo, opa rupi ñande jaiko, cujo significado é quando somos criancas, vivemos por toda parte”. (PEREIRA, 2002, p. 170, grifo do autor).

Segundo o pesquisador, as crianças participam de tudo que acontece na aldeia e são fonte de informação para todos que delas se aproximam; são muito observadoras e dão conta de tudo - da geografia, dos caminhos, das casas, dos moradores.

No grupo familiar ou da parentela, as crianças ensinam e aprendem umas com as outras a nadar, a reconhecer as plantas do entorno, a reconhecer e dominar o espaço da aldeia e a conhecer os costumes, crenças e tradições. Observando as relações de troca na escola é comum as crianças e adolescentes indígenas informarem e/ou ensinarem aos professores índios e não-índios estes saberes, criando um espaço de interculturalidade. Para a criança, na socialização não há problemas de identificação, pois ela se identifica com o que é vivido na família e no grupo social.

Essas observações também são confirmadas pelos professores indígenas que fazem o curso de licenciatura Teko Arandu (UFGD/UCDB) e o curso Ara Verá em nível médio. Elas foram registradas por Nascimento (2007)9 e acrescentam que:

- liberdade significa participar de todos os eventos indígenas, porque todos esses momentos estão sendo vistos pelo nosso Pai Nhanderu;

- a criança significa herdeiro e tem que levar o conhecimento de geração a geração;

- a criança é a esperança para o grupo, para o povo, por isso ela aprende pela oralidade, pelo exemplo, pelos conselhos;

\footnotetext{
${ }^{9}$ Anotações realizadas durante atividades docentes no $2^{\circ}$ semestre de 2006 e $1^{\circ}$ semestre de 2007.
} 
- as crianças também ensinam os menores, também dão "conselhos"; - as crianças percebem e respeitam a organização social da tradição de cada povo;

- é pela ação (socialização) da família que a criança torna-se membro do grupo social;

- as famílias Kaiowá e Guarani nunca veem a criança como adulto, mesmo quando fica adulta;

- uma criança Kaiowá e Guarani é feliz porque ocupa espaço na natureza, quem desenvolve a criança é a natureza.

Decorre destas primeiras percepções que a relação destes povos com o meio ambiente é fundamental para sua cosmologia, espiritualidade e reprodução física e cultural, por isso esta realidade deve constar nas reflexões e nas práticas pedagógicas e curriculares do cotidiano da escola indígena nas aldeias.

Merecem destaque também, em nossas observações, comportamentos que são marcados pela cultura oral e evidenciam um sistema de produção de conhecimento, como a orientação através de conselho, a relação respeitosa entre adultos e crianças, a permissão para iniciativas, para a autonomia na solução de problemas que envolvem a criança, o aprender pela observação atenta e pela imitação dos movimentos dos demais. A oralidade está presente no respeito e escuta atenta e paciente à palavra, especialmente à dos mais velhos. Como os professores também são Kaiowá e Guarani, também eles são perpassados por estes modos de aprender, um modo próprio de ser Guarani.

Por outro lado, as primeiras impressões sobre um estudo com crianças indígenas Kaiowá e Guarani caracterizam também uma primeira sistematização das reflexões que temos feito em torno da temática. Esse exercício traz como indícios os desafios, principalmente metodológicos, que a pesquisa nos tem imposto. Para enfrentar os desafios de aproximação da criança Kaiowá e Guarani compreendemos a necessidade de um aprofundamento epistemológico que nos permita um olhar diferenciado sobre o contexto, histórico, cultural e social em que estas crianças estão inseridas. A construção deste "olhar diferenciado" nos remete a um deslocamento enquanto pesquisadores: a compreensão dos processos de significação que mesmo as crianças fazem, pois partimos do princípio de que "Todas as formas de conhecimento são vistas como o resultado dos aparatos - discursos, práticas, instituições, instrumentos, paradigmas - que fizeram com que fossem construídas como tais". (SILVA, 2007, p. 136).

Para tanto, embora os pesquisadores tenham contato de muitos anos com as comunidades - campos de pesquisa - a primeira percepção foi sobre a necessidade da participação de indígenas como pesquisadores, e não somente 
como "guias" ou informantes, não só pelo domínio da língua indígena, que por si só já constitui um aporte cosmoepistemológico fundamental para o andamento da pesquisa, mas, sobretudo, por ser o olhar indígena Kaiowá e Guarani o mediador dos contatos que visam produzir dados e olhá-los pela lógica que traz junto, como diz o professor Lídio ${ }^{10}$, "o mundo Kaiowá". Neste sentido, professores das duas aldeias, acadêmicos do Curso de Licenciatura para Professores Indígenas Guarani e Kaiowá - UFGD/UCDB, foram integrados à equipe como pesquisadores. No diálogo com eles (visitas às aldeias e oficina sobre metodologia de pesquisa com crianças indígenas) ${ }^{11}$ percebemos que aos procedimentos previstos no projeto teríamos que agregar outros, como:

- entrevistar os professores envolvendo a temática e os objetivos da pesquisa e as práticas pedagógicas vivenciadas por eles;

- mapear e identificar detalhadamente as famílias no contexto das quais seriam observadas as crianças que ainda não frequentam a escola;

- entrevistar os adultos da família tendo como referência as suas relações com as palavras selecionadas como "conteúdos" a serem observados.

A escolha das familias está orientada por critérios como, por exemplo, não pertencer ao chamado "núcleo letrado" da aldeia, representado por professores, agentes de saúde, funcionários da FUNAI, missionários ou lideranças políticas. Foram escolhidas aquelas que estão mais próximas, em seu cotidiano, da oralidade, das famílias extensas, das roças, entre outras particularidades.

Outro cuidado metodológico tem sido ouvir as descrições e interpretações que as crianças fazem das imagens produzidas por elas (desenhos, fotos, filmagens). Existe, ainda, certa resistência ou dificuldade de ambas as partes, isto é, dos pesquisadores, inclusive dos professores índios e das crianças, em estabelecer esta relação e diálogo espontâneo sobre o resultado das atividades - herança, talvez, de práticas pedagógicas centradas na transmissão e regulação dos saberes.

Neste sentido, em alguns momentos, nas oficinas realizadas nas aldeias nos surpreendemos por uma visão ainda borrada de estruturalismo e academicismo. Destacamos como exemplos três situações, expostas a seguir.

1 - Existe a crença de que os conceitos construídos fora da escola estariam mais próximos dos "saberes tradicionais" e os trabalhados na escola seriam resultantes de um diálogo entre os diferentes conceitos de um elemento. Ao conversar com os professores vimos que a criança chega à escola com o

\footnotetext{
${ }^{10}$ Lídio Cabanha, professor kaiowá da aldeia TE’Y KUE, Caarapó, que integra equipe de pesquisa.

${ }^{11}$ Oficina ministrada pelos pesquisadores antropólogos Clarice Cohn/UFSCar e Levi Pereira/UFGD na UCDB $(10-11 / 4 / 2008)$.
} 
conceito de família restrito ao pai, mãe e irmãos, sendo que para os Kaiowá e Guarani, a organização política e social gira em torno da família extensa (parentela e agregados) onde se estabelecem as relações de poder e reciprocidade. Pelos nossos contatos e em nossas visitas às famílias em companhia dos pesquisadores indígenas, percebemos que a rede de parentesco ainda se mantém no espaço geográfico e que a noção de territorialidade da família extensa ainda é vivida, porém esta organização não é percebida pelas crianças, que parecem se orientar por outras referências (mídia, livros didáticos, conteúdos escolares, a recepção de benefícios "por família", entre outros). Isto nos parece caracterizar uma ambivalência nas experiências e construções de representações não só das crianças, mas também dos adultos que vivem estes "entrelugares", nas relações de poder e reciprocidade no que se refere às vivências do dia a dia, como os fenômenos espirituais, culturais, políticos, sociais e da natureza. Como nos ensina Bhabha (2003), precisamos compreender que nenhuma dominação cultural é tão poderosa a ponto de minar os sistemas culturais locais, assim como nenhum sistema local é imune ao colonialismo.

2 - Outra "descoberta” é que as crianças não aprendem só com os adultos, mas também pelo ensino "de geração a geração". Existe uma rede de saberes e ressignificações elaborados nas relações entre elas, constituindo uma pedagogia própria. Esta "descoberta" nos motiva a rever algumas afirmações antropológicas e epistemológicas que evidenciam estereótipos teóricos com relação aos modos de ensinar e aprender entre as chamadas comunidades "nativas" ou tradicionais, como, por exemplo, o de que as crianças só aprendem com os mais velhos, por imitação e repetição. Esses estereótipos foram construídos por uma lógica funcionalista e estruturalista (no contexto da antropologia clássica) e pela invisibilidade que a história tem nos mostrado da criança indígena em estudos desta natureza, sendo ignoradas suas possíveis consequências na construção das subjetividades e identidades em qualquer tempo de vida). Isto é assim compreendido por Bhabha (2003, p. 125):

$\mathrm{O}$ ato de estereotipar não é o estabelecimento de uma falsa imagem que se torna o bode expiatório de práticas discriminatórias. É um texto muito mais ambivalente de projeção e introjeção, estratégias metafóricas e metonímicas, deslocamento, sobredeterminação, culpa, agressividade, o mascaramento e cisão de saberes “oficiais” e fantasmáticos para construir as posicionalidades e oposicionalidades do discurso racista.

3 - Não se percebe a forte "visibilidade invisível" dos processos próprios de aprendizagem que circulam pela escola e pelas salas de aula, por ser este modo de ser de gestores, professores e alunos/crianças o que garante sua cultura e as suas cosmologias, realizando traduções diante das fronteiras que se abrem no contato com outras culturas. 
Cumpre aqui destacar a questão central deste trabalho que é a construção, pelas crianças, de conceitos, de concepções de mundo e território que se sustentam nos chamados "processos próprios de aprendizagem", uma das categorias que caracterizam a educação escolar diferenciada e específica, garantida por lei aos povos indígenas, a qual tem estado muito pouco presente nos debates acadêmicos, fato que constitui uma lacuna nos programas de formação de professores indígenas no Brasil.

\section{Considerações finais}

Como o presente texto é fruto dos resultados preliminares do projeto de pesquisa com as crianças indígenas, algumas contribuições etnográficas e teóricas vão sendo acrescentadas ao longo do seu processo de elaboração. Dessa for$\mathrm{ma}$, após outras viagens às respectivas aldeias (Caarapó e Porto Lindo ${ }^{12}$, alguns novos elementos foram sendo percebidos, como, por exemplo, a espontaneidade das crianças quando estão agrupadas por faixa etária e são convidadas a desenvolver algumas atividades. Tem-se a impressão de que elas estão mais à vontade que os pesquisadores, tamanha a espontaneidade com que interagem durante as atividades de pintura-desenho, filmagem, ou mesmo de entrevistas coletivas. Por outro lado, quando as conversas acontecem na casa destas crianças, junto com a mãe ou com outras pessoas da família, elas se mostram muito retraídas e tímidas, respondendo apenas com monossílabos, às vezes inaudíveis.

Mesmo com as rápidas mudanças ocorridas ultimamente entre os grupos Kaiowá e Guarani, transformações mais impostas do que assumidas e decididas pelo povo, percebe-se em muitas famílias o cuidado com as suas crianças, no sentido de terem receio de antecipar a saída delas para a escola, receio manifestado por dois motivos principais. O primeiro é que, até os sete ou oito anos, a criança deve estar com a família, para aprender a tradição, os ensinamentos dos antigos, aquilo a que chamamos academicamente de socialização primária; e o segundo é que, no entender dos pais, essas crianças na escola correm alguns tipos de risco (são ingênuas, às vezes acontecem brigas e outros tipos de violência física, ou mesmo simbólica), e por isso eles preferem que elas fiquem em casa.

Pudemos constatar, dessa forma, que a cosmovisão da criança indígena Kaiowá e Guarani destas aldeias permanece relacionada aos elementos de seu contexto cultural e relacional, onde a escola - espaço de fronteiras, de reconstrução e ou transformação das cosmovisões - segue exercendo, cada dia mais, um papel decisivo: se antes a escola era tida como elemento que favorecia a dominação e forçava o processo de integração/homogeneização (assimilação, segundo

\footnotetext{
${ }^{12}$ A partir de 2010 a pesquisa se estende para as aldeias Amambai (município de Amambai/MS) e Bororo, na Reserva do município de Dourados/MS.
} 
alguns) à sociedade nacional; na atualidade, assumida pelos índios, mesmo com suas limitações, hoje é vista como instrumento de fortalecimento dos símbolos e códigos culturais, entre eles a língua, o canal de comunicação das representações sociais e da cosmovisão de suas crianças. Não obstante, ainda é possível constatar que, tendo em vista que os processos próprios de aprendizagem, assim como a identidade e a cultura, são dinâmicos, também são passíveis de negociação, de ressignificação e de novas traduções, sem hierarquizar o que é indígena e o que é não indígena, mas que se reescreve na fronteira, por exemplo, entre o conhecimento xamanístico e conhecimento eurocêntrico.

Para outras epistemes, outras práticas e outras formações, compreender os processos próprios de aprendizagem nesta dimensão, mais enfaticamente, para os professores índios, é realizar o exercício da decolonialidade: desaprender o que foi aprendido para voltar a aprender na ótica da recusa à universalidade abstrata (MIGNOLO, 2003).

\section{Referências}

AQUINO, E. V.; NASCIMENTO, A. C.; NELSON, M. de L. C. Educação Escolar: Processos Próprios de Aprendizagem da Criança Guarani/Kaiowá, antes da Escola. In: SEMINÁRIO POVOS INDÍGENAS E SUSTENTABILIDADE: SABERES TRADICIONAIS E FORMAÇÃO ACADÊMICA, 4., 2011, Campo Grande. Anais... Campo Grande: UCDB, 2011. Disponível em: <http://www.neppi.org/eventos/4sustentabilidade/>. Acesso em: 24 mar. 2012.

BHABHA, H. K.. O local da cultura. Belo Horizonte: UFMG, 2003.

BERGAMASCHI, M. A. Prácticas pedagógicas em la aldeã y recreación de la escuela desde la cosmologia Guarani. In: GARCIA, S. M.; PALADINO, M. (Comps.). Educación escolar indígena: investigaciones antropológicas em Brasil y Argentina. Buenos Aires: Antropofagia, 2007. p. 151-170.

BRAND, A. J. . Os novos desafios para a escola e o professor indígena. Série-Estudos, Campo Grande, v. 1, n. 15, p. 59-70, 2003.

CANCLINI, N. G. Culturas híbridas. São Paulo: EDUSP,1998.

COHN, C. Antropologia da criança. Rio de Janeiro: Jorge Zahar, 2005.

ESCOBAR, A. O lugar da natureza e a natureza do lugar: globalização ou pós-desenvolvimento? In: LANDER, E. (Org.). A colonialidade do saber: eurocentrismo e ciências sociais. Buenos Aires: Consejo Latinoamericano de Ciências Sociales - CLACSO, 2005. p. 63-79.

GABRIEL, C. T. Didática crítica multi/intercultural: sobre interlocuções teóricas e construções de objetos. In: CANDAU, V. M. (Org.). Educação intercultural e cotidiano escolar. Rio de Janeiro: 7 Letras, 2006. p. 31-51.

GOMES, A. M. R.; SILVA, R. C. da.; DINIZ L. Infância indígena, escolarização e globalização: uma análise a partir da experiência das escolas indígenas em Minas Gerais. In: 
NASCIMENTO, A. C.; AGUILERA URQUIZA, A. H.; VIEIRA, C. M. N. (Orgs.). Criança Indígena: diversidade cultural, educação indígena e representações sociais. Brasília: Liber Livro, 2011. p. 227-267.

LANDA, B. S. Os Ñandeva-Guarani e o uso do espaço na Terra Indígena Porto Lindo/Jakarey, município de Japorã/MS. 2005. 2 v. 364 f. Tese (Doutorado em História) - Pontifícia Universidade Católica do Rio Grande do Sul, Porto Alegre, 2005.

. Crianças guarani: atividades, uso do espaço a formação do registro arqueológico. In: NASCIMENTO, A. C.; AGUILERA URQUIZA, A. H.; VIEIRA, C. M. N. (Org.). Criança Indígena: diversidade cultural, educação e representações sociais. Brasília: Liber Livro, 2011. p. $45-74$.

LÉVI-STRAUSS, C. O pensamento selvagem. São Paulo: Nacional, 1976.

LOPES DA SILVA, A.; FERREIRA, M. K. L. (Org.). Antropologia, História e Educação - a questão indígena e a escola. São Paulo: Global, 2001.

MALDONADO-TORRES, N. Sobre la colonialidad del ser: contribuciones al desarrollo de un concepto. In: CASTRO-GÓMEZ, S.; GROSFOGUEL, R. (Org.). El giro decolonial: reflexiones para una diversidad epistémica más allá del capitalismo global. Bogotá: Siglo del Hombre Editores, 2007. p. 127-167.

MATO, D. Diferenças Culturais, Interculturalidade e Inclusão na produção de Conhecimentos e Práticas Socioeducativas. In: CANDAU, V. M. (Org.). Educação Intercultural na América Latina: entre concepções, tensões e propostas. Rio de Janeiro: 7 Letras, 2009. p. 74-93.

MIGNOLO, W. Histórias locais/projetos globais: colonialidade, saberes subalternos e pensamento liminar. Belo horizonte: Editora UFMG, 2003.

NASCIMENTO, A. C. A cosmovisão e as representações das crianças Kaiowá/Guarani: o antes e o depois da escolarização. In: REUNIÃO BRASILEIRA DE ANTROPOLOGIA, 25., 2006, Goiânia. Anais... Goiânia, 2006.

NASCIMENTO, A. C.; AGUILERA URQUIZA, A. H.; VIEIRA, C. M. N. Criança Indígena: diversidade cultural, educação indígena e representações sociais. Brasília: Liber Livro, 2011.

NUNES, A. No tempo e no espaço: brincadeiras das crianças A'uwê-Xavante. In: LOPES DA SILVA, A.; MACEDO, A. V. L. da Silva; NUNES, A. (Org.). Crianças indígenas: Ensaios Antropológicos. São Paulo: Global, 2002. p. 64-99

OLIVEIRA, L. F. de.; CANDAU, V. M. F. Pedagogia decolonial e educação antirracista e interculturalidade no Brasil. Educação em Revista, Belo horizonte, v. 26, n. 1, p. 15-40, abr. 2010. DOI: $10.1590 /$ S0102-46982010000100002

PEREIRA, L. M. No mundo dos parentes: a socialização das crianças adotadas entre os Kaiowá. In: LOPES DA SILVA, A.; MACEDO, A. V. L. da S.; NUNES, A. (Org.). Crianças indígenas: ensaios antropológicos. São Paulo: Global, 2002. p. 168-187.

- A socialização da criança kaiowá e guarani: formas de sociabilidade internas às comunidades e transformações históricas recentes no ambiente de vida. In: NASCIMENTO, A. C.; AGUILERA URQUIZA, A. H.; VIEIRA, C. M. N. (Orgs.). Criança Indígena: diversidade cultural, educação indígena e representações sociais. Brasília: Liber Livro, 2011. p. $75-112$. 
PORTO-GONÇALVES, C. W. Apresentação da edição em português. In: LANDER, E. (Org.). A colonialidade do saber: eurocentrismo e ciências sociais. Buenos Aires: Consejo Latinoamericano de Ciências Sociales - CLACSO, 2005. p. 9-15.

SILVA, T. T. da. Documentos de identidade: uma introdução às teorias do currículo. Belo Horizonte: Autêntica, 2007.

TASSINARI, A. M. I. Escola indígena: novos horizontes teóricos, novas fronteiras da educação. In: LOPES DA SILVA, A.; FERREIRA, M. K. L. (Org.). Antropologia, história e educação: a questão indígena e a escola. São Paulo: Global, 2001. p. 44-70.

WALSH, C. Interculturalidade,Crítica e pedagogia Decolonial: in-surgir, re-existir e re-viver. In: CANDAU, V. M. (Org.). Educação intercultural na América Latina: entre concepções, tensões e propostas. Rio de janeiro: 7 Letras, 2009. p. 12-43.

Recebido em 06/06/2012

Versão final recebida em 18/10/2012

Aceito em 20/11/2012 